\title{
The efficacy of the Senior South African Individual Scale Revised in distinguishing between attention deficit hyperactivity disorder, normal and sluggish cognitive tempo children
}

\begin{tabular}{|c|c|}
\hline \multicolumn{2}{|c|}{$\begin{array}{l}\text { Authors: } \\
\text { Leila Abdool Gafc } \\
\text { Alban Burke }^{1} \text { (D) } \\
\text { Jean Fourie }\end{array}$} \\
\hline \multicolumn{2}{|c|}{$\begin{array}{l}\text { Affiliations: } \\
{ }^{1} \text { Centre for Psychological } \\
\text { Services and Career } \\
\text { Development (PsyCaD), } \\
\text { University of Johannesburg, } \\
\text { Johannesburg, South Africa }\end{array}$} \\
\hline \multicolumn{2}{|c|}{$\begin{array}{l}{ }^{2} \text { Department of Education, } \\
\text { Faculty of Education, } \\
\text { University of Johannesburg, } \\
\text { Johannesburg, South Africa }\end{array}$} \\
\hline \multicolumn{2}{|c|}{$\begin{array}{l}\text { Corresponding author: } \\
\text { Leila Abdool Gafoor, } \\
\text { Leilaag@uj.ac.za }\end{array}$} \\
\hline \multicolumn{2}{|c|}{$\begin{array}{l}\text { Dates: } \\
\text { Received: } 11 \text { Dec. } 2020 \\
\text { Accepted: } 18 \text { June } 2021 \\
\text { Published: } 29 \text { July } 2021\end{array}$} \\
\hline \multicolumn{2}{|c|}{$\begin{array}{l}\text { How to cite this article: } \\
\text { Abdool Gafoor, L., Burke, A., } \\
\text { \& Fourie, J. (2021). The } \\
\text { efficacy of the Senior South } \\
\text { African Individual Scale } \\
\text { Revised in distinguishing } \\
\text { between attention deficit } \\
\text { hyperactivity disorder, } \\
\text { normal and sluggish cognitive } \\
\text { tempo children. African } \\
\text { Journal of Psychological } \\
\text { Assessment, 3(0), a45. } \\
\text { https://doi.org/10.4102/ } \\
\text { ajopa.v3i0.45 }\end{array}$} \\
\hline \multicolumn{2}{|c|}{$\begin{array}{l}\text { Copyright: } \\
\text { (C) 2021. The Authors. } \\
\text { Licensee: AOSIS. This work } \\
\text { is licensed under the } \\
\text { Creative Commons } \\
\text { Attribution License. }\end{array}$} \\
\hline \multicolumn{2}{|l|}{ Read online: } \\
\hline 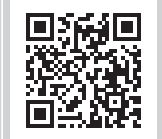 & $\begin{array}{l}\text { Scan this QR } \\
\text { code with your } \\
\text { smart phone or } \\
\text { mobile device } \\
\text { to read online. }\end{array}$ \\
\hline
\end{tabular}

\begin{abstract}
The primary objective of this study was to determine whether attention deficit hyperactivity disorder (ADHD), sluggish cognitive tempo (SCT) and a non-clinical (NC) group of learners perform differently on the Senior South African Individual Scale Revised (SSAIS-R). The rationale for this study is based on literature that argues for SCT to be considered as a separate and unique disorder to ADHD. The SSAIS-R results of 618 (7-17 years of age) children were analysed for the purposes of this study. The total sample consisted of three groups, that is, $\operatorname{ADHD}(n=106), \mathrm{NC}(n=427)$ and SCT $(n=85)$. Between-group $t$-tests were performed to test for significant differences between the three groups with regard to the different SSAIS-R subtests. The results indicated significant differences between NC and ADHD, NC and SCT but not between ADHD and SCT. These results suggest that if SCT is considered to be a separate disorder from ADHD, then this is not evident in terms of the performance on the SSAIS-R. It is recommended that other cognitive and neuropsychological assessments be included in future research to ascertain whether SCT, if it exists, affects performance differently to ADHD.
\end{abstract}

Keywords: cognitive performance; ADHD; SCT; SSAIS-R; attention; cognitive assessments.

\section{Background}

Many factors, such as psychosocial factors, learning disorders and other neurodevelopmental disorders, as described in the Diagnostic and Statistical Manual of Mental Disorders (5th ed.; DSM-5) (American Psychiatric Association [APA], 2013) may affect the academic performance of South African learners. One of the most common neurodevelopmental disorders is attention deficit hyperactivity disorder (ADHD), which is not a homogeneous disorder (Wilens \& Spencer, 2010) as it is erroneously accepted by many practitioners. Prevalence rates in South Africa indicate that approximately $4 \%-5 \%$ of children present with ADHD (Schellack \& Meyer, 2012).

Attention deficit hyperactivity disorder is a complicated, heterogeneous disorder as characterised by the different subtypes described in the DSM-5 (APA, 2013). An additional problem is clinically subthreshold symptoms and comorbid disorders, which complicates the diagnostic process. These problems may result in either over- or mis-diagnosis of ADHD (Barkley, 2013). In addition, there seems to be a lack of standardised diagnostic procedures to assist with making a clear diagnosis.

Levy, Hay, McStephen, Wood and Waldman (1997) suggested that it may be better to describe ADHD as a spectrum disorder where symptoms of attention, inhibition and motor activity regulation are placed on a continuum. As our understanding of ADHD became clearer it has become evident that ADHD is a complex developmental impairment that extends further than merely a problem of inattention (Brown, 2002). Although some authors such as Milich, Balentine and Lynam (2001) placed an emphasis on attention problems, other authors such as Barkley (1998) argued that ADHD is a result of impaired inhibitory processes. As a result of the different opinions regarding the role of inattentiveness in ADHD there have been questions regarding the validity of the inattentive subtype of $\mathrm{ADHD}$ and whether this subtype should not rather be considered to be a separate and unique disorder (Barkley, 1998, 2001, 2016; Lahey, 2001).

In this regard, both Barkley $(2013,2014)$ and Becker (2019) have suggested that sluggish cognitive tempo (SCT) be both similar and different from ADHD. The overlap seems to be mainly between SCT and ADHD of the inattentive subtype as illustrated by the following symptoms of 
SCT: daydreaming, hypo-arousal, confusion, objectively inattentive, lethargy, slow psychomotor speed, difficulty in following instructions, drowsiness, apathy, internally distracted, slow task completion, lack of initiative and decline in sustained performance (Barkley, 2018). The main difference between these two disorders seems to be that ADHD is characterised by external distractibility whereas SCT seems to be characterised by internal distractibility (Becker \& Barkley, 2021). Furthermore, impulsivity is one of the core categories of symptoms in ADHD but is not a distinct symptom or cluster of symptoms of SCT (Barkley, 2005). Another difference between the two disorders is that children with ADHD tend to struggle with productivity whereas children with SCT tend to struggle with accuracy (Barkley, 2013).

The pathogenesis of the two disorders also seem to be different (see Table 1), ADHD is characterised by an early onset whereas SCT is characterised by a later onset (Barkley, 2005). Bruchmüller, Margraf and Schneider (2012) found in the South African context that ADHD not only starts in childhood but persisted into adolescence in most cases. It also seems as if there is stronger evidence for ADHD being hereditary than SCT (Barkley, 2005).

Different socio-economic factors seem to play a role in these two disorders (Barkley, 2012, 2013). Sluggish cognitive tempo seems to be more prevalent in lower socio-economic groups than ADHD (Barkley, 2012) and that, per implication, SCT might be associated more with psychosocial difficulties than ADHD.

The two disorders also seem to differ with regard to comorbid conditions where children with SCT are more prone to

TABLE 1: Differences between sluggish cognitive tempo versus attention deficient hyperactivity disorder.

\begin{tabular}{|c|c|c|}
\hline Variable & SCT & ADHD \\
\hline \multirow[t]{6}{*}{$\begin{array}{l}\text { Clinical } \\
\text { manifestation }\end{array}$} & $\begin{array}{l}\text { SCT forms two dimensions of } \\
\text { symptoms distinct from ADHD } \\
\text { (Daydreaming and sluggish) }\end{array}$ & $\begin{array}{l}\text { Symptoms of SCT distinct from } \\
\text { ADHD }\end{array}$ \\
\hline & $\begin{array}{l}\text { SCT has a later onset of } \\
\text { symptoms }\end{array}$ & $\begin{array}{l}\text { ADHD has an earlier onset of } \\
\text { symptoms }\end{array}$ \\
\hline & SCT symptoms increase with age & $\begin{array}{l}\text { ADHD symptoms decline or } \\
\text { stabilise }\end{array}$ \\
\hline & $\begin{array}{l}\text { SCT symptoms are slightly more } \\
\text { severe in males than females }\end{array}$ & $\begin{array}{l}\text { ADHD symptoms more severe in } \\
\text { males than females }\end{array}$ \\
\hline & $\begin{array}{l}\text { No inhibition problems or } \\
\text { impulsivity (overly inhibited) }\end{array}$ & $\begin{array}{l}\text { Inhibition and impulsivity } \\
\text { problems }\end{array}$ \\
\hline & $\begin{array}{l}\text { Impaired in school performance: } \\
\text { Accuracy disorder (especially } \\
\text { Mathematics as the ability shares } \\
\text { genetics with ADHD I) }\end{array}$ & $\begin{array}{l}\text { Impaired in school performance: } \\
\text { Productivity disorder }\end{array}$ \\
\hline \multirow[t]{4}{*}{ Comorbidity } & $\begin{array}{l}\text { Rarely shows aggression or } \\
\text { oppositional defiant disorder } \\
\text { symptoms }\end{array}$ & $\begin{array}{l}\text { Shows aggression or oppositional } \\
\text { defiant disorder symptoms }\end{array}$ \\
\hline & $\begin{array}{l}\text { Greater risk for internalising } \\
\text { symptoms (anxiety and } \\
\text { depression) (even after } \\
\text { controlling for ADHD-I) }\end{array}$ & $\begin{array}{l}\text { Less risk for internalising } \\
\text { symptoms (anxiety and } \\
\text { depression) (even after } \\
\text { controlling for ADHD-I) Greater } \\
\text { risk for externalising disorder }\end{array}$ \\
\hline & $\begin{array}{l}\text { Linked to different personality } \\
\text { traits: }\end{array}$ & $\begin{array}{l}\text { Linked to different personality } \\
\text { traits: }\end{array}$ \\
\hline & $\begin{array}{l}\text { Punishment sensitivity and } \\
\text { shyness or fear }\end{array}$ & Reward sensitivity and risk taking \\
\hline
\end{tabular}

Source: Barkley, 2005, 2011a, 2011b, 2012, 2013, 2014.

Note: Please see the full reference list of the article, Abdool Gafoor, L., Burke, A., \& Fourie, J. (2021). The efficacy of the Senior South African Individual Scale Revised in distinguishin between attention deficit hyperactivity disorder, normal and sluggish cognitive tempo children. African Journal of Psychological Assessment, 3(0), a45. https://doi.org/10.4102/ ajopa.v3i0.45, for more information.

$\mathrm{SCT}$, sluggish cognitive tempo; ADHD, attention deficient hyperactivity disorder internalising disorders whereas children with ADHD are more prone to externalising disorders (Barkley, 2005, 2011a, 2011b, 2012).

Although there may be some overlap between the symptoms of ADHD and SCT it is not only a question of semantics but more importantly a question in terms of treatment and management of children with SCT. Attention deficit hyperactivity disorder is a neurologically based disorder, which is characterised by a persistent pattern of inattention and or hyperactivity-impulsivity that interferes with function or development (APA, 2013).

Some researchers argue that SCT is nothing more than ADHD of the inattentive subtype (Jacobson et al., 2012) whereas others argue that SCT could be conceptualised as a separate disorder (Barkley, 2016; Becker, 2013). However, many critics highlight a lack of a clear clinical description of SCT and are also opposed to the name of the disorder as they view this as derogatory and misleading. As far as the latter is concerned there have been suggestions to change the name to concentration deficient disorder (CDD), which would be less offensive, keep the concentration of the label on the disorder and summarise the core deficiency (Barkley, 2014; Becker, 2013).

Current studies on SCT are gaining international momentum (Lee et al., 2016), but none have been carried out in South Africa. Given the link between SCT and various psychosocial, socio-economic and cultural factors, it is important to investigate the possibility of SCT in the South African context, as one cannot underestimate the contribution of cultural influences on mental health (Achenbach \& Rescorla, 2007).

There is a distinct need for further research, both nationally and internationally into SCT, especially as far as aetiology, diagnosis and treatment are concerned. Accurate descriptions of SCT symptoms may help to predict areas of functional difficulty in learners with poor academic performance (Jacobson et al., 2012). In this regard, slow processing speed, which seems to be mainly attributed to ADHD and low arousal levels have been identified in children with SCT (Shanahan et al., 2006), which may explain poor academic performance.

Although Becker (2019) argued that validated measures can be used to examine SCT symptoms in different cultures, the reliability and validity of psychometric instruments, such as the Senior South African Individual Scale Revised (SSAIS-R), that are used in South Africa remain a problem. Many, if not most of these assessments are outdated and have not been standardised for all cultural and language groups. Foxcroft, Paterson, Le Roux and Herbst (2004) stated that it is concerning that most tests that are being used by practitioners have not been adapted for the South African multicultural context but continue to be used for a wide variety of purposes such as identifying and diagnosing psychiatric conditions. There is, however, clearly a void in the development and improvement of psychometric assessments in South Africa, 
which is not being filled. As a result, practitioners have no other option than to use existing assessments despite all the problems mentioned here.

Although the existence of a disorder such as SCT is debateable, the premise of this study is that it possibly exists as a distinct disorder from ADHD and that performance on the SSAIS-R would differ significantly from each other. It is hypothesised that both these groups would perform significantly poorer on the SSAIS-R than the NC group.

\section{Method}

A comparative research design was used to determine whether there are significant differences on the SSAIS-R amongst the three groups.

\section{Participants}

Archival data were used for the purposes of this study. Purposive sampling was used where 734 clinical files of children between the ages of 7 and 17 years, where the SSAIS-R was performed, were perused. These cases were then categorised into three groups: an ADHD group ( $n=106$, $17 \%)$, a SCT group $(n=85,14 \%)$ and a NC group $(n=427$, $69 \%$ ) and 103 cases were excluded. Based on the clinical notes in the files, a formal diagnosis by mental health professionals of ADHD was used as the including criterion for the ADHD group, the proposed symptoms of SCT as described by Barkley (2005, 2011a, 2011b, 2012, 2013, 2014) was used as including criteria for the SCT group. Cases with no clear disorders or diagnoses were included in the NC group and cases where there was evidence of other disorders were excluded from the study.

From Table 2 it can be deduced that there was not an equal distribution of males and females in the sample $\left(\mathrm{Chi}^{2}=8.82\right.$; $p=0.01$ ). However, given the higher prevalence rate of ADHD in males than females, the ADHD sample could be accepted as an accurate reflection of the demographics of children with neurodevelopmental disorders. It is difficult to conclude whether the higher prevalence rate of SCT in males and females in this study is representative of the SCT population.

The higher number of males than females in the NC group is, however, of concern as this does not reflect the gender distribution in the normal population.

\begin{tabular}{lccccccc}
\multicolumn{7}{l}{ TABLE 2: Gender distribution in the three groups. } \\
\hline Group & Variable & Male & Female & Total & Chi $^{2}$ & df & $\boldsymbol{p}$ \\
\hline ADHD & Observed & 76 & 30 & 106 & 8.82 & 2 & 0.012 \\
& Expected & 67 & 39 & - & - & - & - \\
\multirow{2}{*}{ NC } & Observed & 253 & 174 & 427 & - & - & - \\
& Expected & 268 & 158 & - & - & - & - \\
\multirow{2}{*}{ SCT } & Observed & 61 & 24 & 85 & - & - & - \\
& Expected & 54 & 31 & - & - & - & - \\
\hline Total & - & $\mathbf{3 9 0}$ & $\mathbf{2 2 8}$ & $\mathbf{6 1 8}$ & - & - & - \\
\hline
\end{tabular}

$\mathrm{NC}$, non-clinical; SCT, sluggish cognitive tempo; $\mathrm{ADHD}$, attention deficient hyperactivity disorder.
The race distribution of the sample is not an accurate reflection of the demographics of the general South African population; however, given the absence of prevalence rates of neurodevelopmental disorders per race group available, it is difficult to conclude whether the sample is representative of the general population. It must be observed that despite the SSAIS-R not being standardised for black South African learners, practitioners still use this test for psycho-educational purposes.

Although only data for learners between the ages of 7 and 17 years were included in the study there was not an equal representation of all the age groups $\left(\mathrm{Chi}^{2}=101.5 ; p<0.000\right)$. This is, however, not surprising as both ADHD and SCT are identified at a young age whereas the learners in the NC group did not necessarily experience psycho-educational problems, which would explain why they only requested assessments at a later age (see Table 3).

\section{Instrument}

Despite the SSAIS-R not being standardised for the South African population, as the norms are limited to white, mixed race and Indian groups, practitioners continue to use the SSAIS-R for psycho-educational and diagnostic purposes for children between the ages of 7 and 17 years. When data were retrieved from the case files, most of the cases had SSAIS-R data and only in a couple of cases were other assessments such as the WISC-IV utilised. Based on this, only the cases where the SSAIS-R was used was included in the study. Skills such as learning ability, general knowledge, spatial perception, visual motor skills, basic perceptual and concept performing skills are measured (Van Eeden, 1991). The SSAIS-R typically evaluates a level of general intelligence and strengths and weaknesses (Van Eeden, 1997).

Raw scores of the test are converted into norm scores for different age categories. The reliability varies from one subtest and one age group to another. The lowest reliability score was 0.59 for the missing parts subtest for the 13-year-old age group and the highest was 0.91 for ages 8,10 and 12 year olds (Laher \& Cockcroft, 2013). The construct validity of the SSAIS-R was determined by both factor analysis, which yielded two broad

TABLE 3: Age distribution in the three groups.

\begin{tabular}{|c|c|c|c|c|c|c|c|}
\hline \multirow[t]{2}{*}{ Age in years } & \multicolumn{3}{|c|}{ Group } & \multirow[t]{2}{*}{ Total } & \multirow[t]{2}{*}{$\mathrm{Chi}^{2}$} & \multirow[t]{2}{*}{ df } & \multirow[t]{2}{*}{$p$} \\
\hline & ADHD & NC & SCT & & & & \\
\hline 7 & 2 & 8 & 5 & 15 & 101.51 & 18 & 0.000 \\
\hline 8 & 17 & 32 & 15 & 64 & - & - & - \\
\hline 9 & 17 & 35 & 13 & 65 & - & - & - \\
\hline 10 & 12 & 28 & 13 & 53 & - & - & - \\
\hline 11 & 8 & 26 & 9 & 43 & - & - & - \\
\hline 12 & 15 & 14 & 11 & 40 & - & - & - \\
\hline 13 & 10 & 22 & 2 & 34 & - & - & - \\
\hline 14 & 10 & 88 & 7 & 105 & - & - & - \\
\hline 15 & 12 & 136 & 9 & 157 & - & - & - \\
\hline 16 & 3 & 38 & 1 & 42 & - & - & - \\
\hline Total & 106 & 427 & 85 & 618 & - & - & - \\
\hline
\end{tabular}
disorder. 
factors, that is, verbal and non-verbal and correlation with a similar test that measures the same construct. The different subtests in Table 4 were categorised in terms of either verbal or non-verbal tests. One of the subtests, that is, number problems loaded on both the verbal and non-verbal scores, however, the test developers decided to categorise this as a verbal test. Another anomaly was the Form Board test that did not load significantly on the two main factors, although it contributes to measuring non-verbal intelligence and was therefore categorised in the non-verbal scale.

The scores of the composite scales of the SSAIS-R were correlated with other tests that measure similar constructs. Van Eeden (1997) reported that subtests on the SSAIS-R correlated significantly with scores on similar tests.

\section{Procedure}

All the files of children who were referred for psychoeducational assessments in the period 2006-2018 were studied and only those cases where SSAIS-R assessments were carried out were included initially. The diagnostic criteria for ADHD as outlined in the DSM-5 and SCT as described by Barkley (2011a, 2011b, 2012) were used to identify cases for these two groups. Each case was reviewed

TABLE 4: Subtests and descriptors of the Senior South African Intelligence Scale Revised that were utilised in this study.

\begin{tabular}{|c|c|}
\hline Subtests & Descriptors \\
\hline \multicolumn{2}{|c|}{ Verbal scale-Verbal intelligence and verbal learning ability } \\
\hline Vocabulary & Long-term memory and concept formation \\
\hline Comprehension & Comprehension, logical reasoning \\
\hline Similarities & $\begin{array}{l}\text { Abstract, functional and concrete reasoning. Verbal concep } \\
\text { formation. Long-term memory }\end{array}$ \\
\hline Number problems & $\begin{array}{l}\text { Numerical reasoning, logical reasoning, abstract thought. } \\
\text { Basic mathematical computations. }\end{array}$ \\
\hline Story memory & Short-term auditory memory, logical memory \\
\hline \multicolumn{2}{|c|}{ Non-verbal scale-Non-verbal intelligence and non-verbal learning ability } \\
\hline Pattern completion & $\begin{array}{l}\text { Measures the processes underlying logical thinking, } \\
\text { accurate visual perception, concrete reasoning, } \\
\text { concentration }\end{array}$ \\
\hline Block design & $\begin{array}{l}\text { Non-verbal intelligence and non-verbal problem solving, } \\
\text { logical reasoning, perceptual organisation, spatial } \\
\text { visualisation and orientation, abstract conceptualisation, } \\
\text { concentration, visual-motor coordination }\end{array}$ \\
\hline Missing parts & $\begin{array}{l}\text { Visual concentration, organisation, visual memory, verbal } \\
\text { comprehension }\end{array}$ \\
\hline Form board & $\begin{array}{l}\text { Visual perception, visual organisation, visual concept } \\
\text { formation, visual-motor coordination, sensory-motor } \\
\text { feedback }\end{array}$ \\
\hline Memory for digits & $\begin{array}{l}\text { Auditory short-term memory for numbers, attention, } \\
\text { concentration, mechanical memory, mental control }\end{array}$ \\
\hline Coding & $\begin{array}{l}\text { Visual-associative learning ability, psychomotor speed, } \\
\text { visual-motor integration and coordination, attention, } \\
\text { concentration, motivation, short-term memory }\end{array}$ \\
\hline
\end{tabular}

Source: Adapted from Van Eeden, R. (1991). Manual for the Senior South African Individual Scale-Revised (SSAIS-R). Part 1: Background and standardization. Pretoria: Human Sciences Research Council.

TABLE 5: Race distribution in the three groups.

\begin{tabular}{lcccccccccc}
\hline Group & $\begin{array}{c}\text { Not } \\
\text { mentioned }\end{array}$ & African & $\begin{array}{c}\text { Mixed } \\
\text { race }\end{array}$ & Indian & White & Total & Chi $^{2}$ & df & $p$ \\
\hline ADHD & 0 & 32 & 13 & 4 & 57 & 106 & 19.04 & 8 & .015 \\
NC & 3 & 107 & 36 & 15 & 266 & 427 & - & - & - \\
SCT & 0 & 33 & 11 & 7 & 34 & 85 & - & - & - \\
\hline Total & $\mathbf{3}$ & $\mathbf{1 7 2}$ & $\mathbf{6 0}$ & $\mathbf{2 6}$ & $\mathbf{3 5 7}$ & $\mathbf{6 1 8}$ & - & - & - \\
\hline
\end{tabular}

$\mathrm{NC}$, non-clinical; SCT, sluggish cognitive tempo; $\mathrm{ADHD}$, attention deficient hyperactivity disorder. independently by two ratters and only the cases where there was agreement between the two ratters in terms of which group the cases should be categorised in were ultimately included in the final sample. The diagnosis, as reported in the file, was verified by the observations that were reported in the file. Those cases where there were discrepancies between the diagnosis and the observations were excluded. It is unfortunate that many mental health professionals do not distinguish between the different subtypes of ADHD when reporting the diagnosis. As a result of this the ADHD group could not be sub-categorised in terms of subtypes.

Identifying the SCT group proved to be challenging because of several reasons. In the absence of an official diagnostic category for SCT, mental health professionals in South Africa have not and do not make an SCT diagnosis. In order to overcome this problem, those cases where there was evidence of concentration and attention difficulties but no formal ADHD diagnosis, as well as the typical signs and symptoms of SCT, as reported in the literature, were used to categorise these cases as SCT. Cases where there was evidence of a related neurological impairment, such as epilepsy, were excluded. It is acknowledged that this process may have yielded both false positive and false negative categorisations of SCT and ADHD.

Cases where there were no indications of any pathology were categorised as NC. Those cases where there was evidence of other forms of pathology were excluded.

\section{Data analysis}

The aim of study was to determine whether there would be a difference in the performance of ADHD, SCT and NC learners on the SSAIS-R. This dictates that statistical procedures that compare means between groups to be utilised to investigate the demographic composition of these three groups descriptive statistics were calculated (see Tables 2, 3 and 5). Descriptive statistics, that is, mean and standard deviations were calculated for all the subtests and the composite scores.

To determine whether the differences between the three groups were statistically significant, in-between group $t$-tests were calculated. Levene's test for the equality of variances was calculated and it was found that variances for the different subtests and different groups varied between 15\% and $30 \%$ being unequal. It was decided to report parametric statistical analysis, that is, the $t$-test, as opposed to the nonparametric equivalent, that is, the Mann-Whitney $U$ test. Both the $t$-test and the Mann-Whitney $U$ test was run on the data and both produced the same results.

Maher, Markey and Ebert-May (2013) are of the opinion that the metrics of effect size provides additional information to the reporting of probability as the effect size provides information on the magnitude of the differences between variables, whereas the significance test indicates the likelihood that the difference is because of chance. Significance is sensitive to sample size and has the potential to be flawed, 
therefore these authors suggest that researchers should report effect size in addition to significance as this would inform them whether their findings are practically meaningful or important (Pallant, 2013; Sullivan \& Feinn, 2012). For this reason, Cohen's $d$ was calculated and reported in the results. An effect size of 0.2 is small, 0.5 is medium and 0.8 and above is large (Cohen, 1992).

\section{Ethical considerations}

The parents of the minor learners who come to the clinic for assessments are required to complete a consent form. This form has a section that gives permission for using information for research and training purposes. All data were captured by file number thus there were neither identifying details nor any identifying information used in the reporting of the results therefore it would be impossible to identify individuals from the results of the study. Ethical clearance was provided by the Faculty of Education, Research Ethics Committee at the University of Johannesburg, reference number: SEM 2 2018-029.

\section{Results}

From Table 6 it is evident that the NC group generally scored better than the other two groups and the ADHD group generally scored better than the SCT group in most of the subtests.

As reported previously the NC group performed significantly better in the subtests than both the other groups (see Table 7). Although the SCT and the ADHD groups did perform differently on the subtests, none of these differences were significant (see Table 7). When looking at the effect sizes (Cohen's $d$ ), it can be seen that despite significant differences the effect sizes were small to medium indicating that in the verbal subtests the SSAIS-R were not good predictors in distinguishing between ADHD, NC and SCT.

The NC group performed significantly better than the other two groups on the Form Board subtest (see Table 8). When

TABLE 6: Mean and standard deviation scores of the different subtests for the three groups.

\begin{tabular}{|c|c|c|c|c|c|c|c|c|}
\hline \multirow[t]{2}{*}{ Variable } & \multicolumn{2}{|c|}{ Total $(n=618)$} & \multicolumn{2}{|c|}{ ADHD $(n=106)$} & \multicolumn{2}{|c|}{ NC $(n=427)$} & \multicolumn{2}{|c|}{ SCT $(n=85)$} \\
\hline & $M$ & SD & $M$ & SD & $M$ & SD & $M$ & SD \\
\hline Vocabulary & 9.19 & 3.27 & 9.23 & 2.73 & 9.24 & 3.30 & 9.24 & 3.58 \\
\hline Comprehension & 9.51 & 4.50 & 7.97 & 3.50 & 10.32 & 4.66 & 7.74 & 3.62 \\
\hline Similarities & 9.38 & 4.28 & 8.55 & 4.22 & 9.95 & 4.15 & 7.99 & 4.31 \\
\hline Number Problem & 8.03 & 3.72 & 7.42 & 3.35 & 8.50 & 3.72 & 6.67 & 3.41 \\
\hline Story memory & 8.61 & 3.76 & 8.05 & 3.44 & 9.00 & 3.78 & 7.53 & 3.63 \\
\hline Pattern completion & 9.85 & 4.27 & 10.08 & 4.02 & 10.03 & 4.23 & 9.01 & 4.54 \\
\hline Block design & 9.60 & 3.30 & 9.03 & 3.81 & 9.96 & 2.94 & 8.81 & 3.87 \\
\hline Missing parts & 9.57 & 3.41 & 8.98 & 3.16 & 9.96 & 3.39 & 8.73 & 3.51 \\
\hline Form board & 10.15 & 4.16 & 10.26 & 5.05 & 10.52 & 3.91 & 8.34 & 3.86 \\
\hline Memory for digits & 8.66 & 3.39 & 8.13 & 2.96 & 8.99 & 3.36 & 7.67 & 3.79 \\
\hline Coding & 8.70 & 4.11 & 8.44 & 4.98 & 9.00 & 3.97 & 7.62 & 3.38 \\
\hline Verbal & 93.45 & 20.96 & 88.14 & 16.69 & 96.61 & 21.45 & 86.53 & 18.43 \\
\hline Non-verbal & 98.08 & 19.11 & 95.80 & 16.96 & 100.33 & 18.82 & 91.65 & 20.28 \\
\hline Full scale & 95.23 & 20.62 & 90.76 & 16.81 & 98.29 & 20.83 & 87.60 & 19.52 \\
\hline
\end{tabular}

$\mathrm{NC}$, non-clinical; SCT, sluggish cognitive tempo; ADHD, attention deficit hyperactivity disorder. looking at the effect size (Cohen's $d$ ) of the non-verbal subtests, again the effect sizes were found to be small to medium indicating that the size of the differences between the ADHD, NC and SCT groups on the non-verbal subtests were not large despite the NC group performing significantly better on the Form Board and coding subtests. This again refers to the SSAIS-R not being a good predictor in distinguishing between ADHD, NC and SCT.

\section{Discussion}

This study investigated the differences in performance of ADHD, SCT and NC on the SSAIS-R. Although there were significant differences between the ADHD and NC groups and the NC and the SCT group the effect sizes were only small to medium. The NC group performed significantly better than the other two groups on tests that were either on a time completion limit or where the time to complete a task is factored into the scoring of that test, however the effect sizes on these tests were also small to medium.

Barkley (2012) and Lee et al. (2016) argued that SCT and ADHD are two separate and distinct disorders, however, the only significant differences that were found in this study were that the ADHD group performed better than the SCT group on the Form Board and coding subtests. This finding is in line with the findings of the research performed by Flannery, Luebbe and Becker (2017) that children with ADHD generally perform better on perceptual motor tasks than children with SCT. As opposed to the SCT group the ADHD group did not differ significantly from the NC group on these two subtests. It would therefore seem as if learners with SCT tend to make more errors on these tasks than either the ADHD or the NC

TABLE 7: $t$-test scores for the differences in the mean scores of the verbal subtests between the three groups.

\begin{tabular}{|c|c|c|c|c|c|c|c|c|c|}
\hline \multirow[t]{2}{*}{ Variable } & \multicolumn{3}{|c|}{ ADHD vs. NC } & \multicolumn{3}{|c|}{ ADHD vs. SCT } & \multicolumn{3}{|c|}{ NC vs. SCT } \\
\hline & $T$ & $P$ & $\bar{d}$ & $t$ & $p$ & $d$ & $t$ & $p$ & $d$ \\
\hline tent & -0.029 & 0.979 & 0.0 & -0.02 & 984 & 0.0 & 0.00 & 0.998 & 0.0 \\
\hline Comprehension & -4.850 & $0.000 * * *$ & 0.0 & 0.45 & 0.656 & 0.0 & 4.82 & $0.000 * * *$ & 0.0 \\
\hline Similarities & -3.100 & $0.002 * *$ & -0.3 & 0.90 & 0.369 & 0.5 & 3.95 & $0.000 * * *$ & 0.5 \\
\hline Number Problem & -2.720 & $0.007^{* *}$ & -0.3 & 1.54 & 0.126 & 0.5 & 4.20 & $0.000 * * *$ & 0.5 \\
\hline Story Memory & -2.370 & $0.018^{*}$ & -0.3 & 1.01 & 0.314 & 0.4 & 3.30 & $0.001 * *$ & 0.4 \\
\hline /erbal & -3.770 & $0.000 * * *$ & -0.5 & 0.63 & 0.531 & 0.5 & 3.99 & $0.000 * * *$ & 0.5 \\
\hline
\end{tabular}

NC, non-clinical; SCT, sluggish cognitive tempo; ADHD, attention deficit hyperactivity disorder.

***, $p<0.001 ; * *, p<0.01 ; *, p<0.05$.

TABLE 8: $t$-test scores for the differences in the mean scores of the non-verbal subtests between the three groups.

\begin{tabular}{|c|c|c|c|c|c|c|c|c|c|}
\hline \multirow[t]{2}{*}{ Variable } & \multicolumn{3}{|c|}{ ADHD vs. NC } & \multicolumn{3}{|c|}{ ADHD vs. SCT } & \multicolumn{3}{|c|}{ NC vs. SCT } \\
\hline & $t$ & $p$ & $\bar{d}$ & $t$ & $p$ & $d$ & $t$ & $p$ & $d$ \\
\hline Pattern completion & 0.09 & 0.925 & 0.0 & 1.72 & 0.088 & 0.2 & 2.01 & $0.045^{*}$ & 0.2 \\
\hline Block design & -2.76 & $0.006 * *$ & -0.2 & 0.39 & 0.699 & 0.4 & 3.12 & $0.002 * *$ & 0.4 \\
\hline Missing parts & -2.70 & $0.007 * *$ & -0.3 & 0.52 & 0.603 & 0.4 & 3.04 & $0.002 * *$ & 0.4 \\
\hline Form board & -0.58 & 0.564 & -0.1 & 2.89 & $0.004 * *$ & 0.5 & 4.72 & $0.000 * * *$ & 0.5 \\
\hline Memory for digits & -2.39 & $0.017^{*}$ & -0.3 & 0.95 & 0.346 & 0.4 & 3.22 & $0.001 * *$ & 0.4 \\
\hline Coding & -1.24 & 0.215 & -0.1 & 1.29 & 0.199 & 0.4 & 2.99 & $0.003 *$ & 0.4 \\
\hline Non-verbal & -2.25 & $0.025^{*}$ & -0.2 & 1.53 & 0.128 & 0.4 & 3.79 & $0.000 * * *$ & 0.4 \\
\hline
\end{tabular}


groups. Both the Form Board and coding subtests measure perceptual motor speed to a greater or lesser extent.

\section{Conclusion}

There were several limitations to this study, which may have affected the results and conclusions. Archival data were used therefore the reports of many practitioners perused and discrepancies in test administration, scoring and interpretation cannot be accounted for in this study. A further limitation is that these practitioners used the SSAIS-R even though the test is not standardised for all race groups in South Africa and this may also have affected the results of the study.

Keeping these limitations in mind, the results indicated that the ADHD and SCT groups differed significantly from the NC group, implying that they are more similar in terms of performance on the SSAIS-R than they would be to the NC group. It might be worthwhile to describe these two disorders in terms of an attention spectrum and to investigate which aspects of attention differ between these two groups. Both the ADHD and SCT groups differed significantly from the NC group, however the SCT group differed significantly on more of the SSAIS-R subtests from the NC group than did the ADHD group.

When considering disorders such as SCT and ADHD, it may be more appropriate to categorise these two disorders together as disorders of attention. If one accepts that attention as a construct, would be normally distributed in the general population, both the SCT and ADHD groups would have impaired attention. This would also be in line with the suggestion that SCT should rather be named CDD (Barkley, 2014; Becker, 2013) as it focuses on the impairment of attention and concentration of the disorder. Further investigation is necessary to determine whether there are attention differences between ADHD and SCT, as well as to determine the locus of distraction, that is, either internal or external (see Table 1).

It is recommended that other forms of assessment, such as neuropsychological assessments should be considered when drawing a distinction between these two disorders. Burke, Austin and Waldeck (2011) argued that a diagnosis of ADHD must only be made based on multiple measures such as psychometric assessments, neuropsychological assessments, behavioural observations and physiological measures. In addition, the clinical observations during a test session, keeping Barkley's symptoms of SCT in mind, would be essential as the reason for poor performance and a reason for inattentiveness that would differ between ADHD and SCT. It can be expected that both would perform poorly on cognitive assessments for different reasons. It is expected that learners with ADHD would battle to remain undistracted, show signs of impulsivity and would be hyperactive whilst those with SCT would battle to respond timeously and would require prompting and guidance to sustain their effort.
Given the fact that results suggest that the performance on the SSAIS-R subtests did not differ significantly between the ADHD and SCT groups we draw one of two conclusions. It could be that ADHD and SCT are not two distinct disorders as suggested by Becker and Barkley (2021) or that the two groups perform similarly on a cognitive assessment such as the SSAIS-R.

\section{Acknowledgements}

The authors would like to thank the team of Intern Psychometrists who captured the data for this article over 2017 and 2018.

\section{Competing interests}

The authors declare that they have no financial or personal relationships that may have inappropriately influenced them in writing this article.

\section{Authors' contributions}

L.A.G. contributed $40 \%$ towards the article in literature review, results, conclusion, discussion and referencing. A.B. contributed $40 \%$ towards the article in data analysis, results and the conclusion. J.F. contributed $20 \%$ towards the article in editing and conclusion.

\section{Funding information}

This research project is supported through an earmarked grant allocated as part of the Teaching and Learning Development Capacity Improvement Programme (TLDCIP), a partnership between the Department of Higher Education and Training and the European Union.

\section{Data availability}

Data sharing is not applicable to this article as no new data were created or analysed in this study.

\section{Disclaimer}

The views and opinions expressed in this article are those of the authors and do not necessarily reflect the official policy or position of any affiliated agency of the authors.

\section{References}

Achenbach, T.M., \& Rescorla, L.A. (2007). Multicultural supplement to the manual for the ASEBA school-age forms \& profiles. Burlington: University of Vermont, Research Center for Children, Youth \& Families.

American Psychiatric Association. (2013). Diagnostic and statistical manual of menta disorders (5th ed.). Washington, DC: American Psychiatric Association.

Barkley, R.A. (1998). Attention-deficit hyperactivity disorder: A handbook for diagnosis and treatment (2nd ed.). New York: Guilford.

Barkley, R.A. (2001). The executive functions and self-regulation: An evolutionary neuropsychological perspective. Neuropsychology Review, 11, 1-29. https://doi. org/10.1023/A:1009085417776

Barkley, R.A. (2005). ADHD and the nature of self-control (paperback ed.). New York, NY: Guilford.

Barkley, R.A. (2011a). The Barkley adult ADHD rating scale - IV. New York, NY: Guilford. Barkley, R.A. (2011b). The Barkley deficits in executive functioning scale. New York, NY: Guilford. 
Barkley, R.A. (2012). Distinguishing sluggish cognitive tempo from attention deficit hyperactivity disorder in adults. Journal of Abnormal Psychology, 121(4), 978-990. https://doi.org/10.1037/a0023961

Barkley, R.A. (2013). Two types of attention disorders now recognized by clinical scientists. In: Taking charge of ADHD: The complete, authoritative guide for parents (3rd ed., pp. 20-25). New York, NY: Guilford.

Barkley, R.A. (2014). Sluggish cognitive tempo (concentration deficit disorder?): Status, future directions, and a plea to change the name. Journal of Abnormal Child Psychology, 42, 117-125. https://doi.org/10.1007/s10802-013-9824-y

Barkley, R.A. (2016). A brief note on the history of executive functioning. The ADHD Report, 24(1), 14. https://doi.org/10.1521/adhd.2016.24.1.14

Barkley, R.A. (2018). Barkley Sluggish Cognitive Tempo Scale - Children and Adolescents (BSCTS-CA). New York, NY: Guilford.

Becker, S.P. (2013). Topical review: Sluggish cognitive tempo: Research findings and relevance for paediatric psychology. Journal of Paediatric Psychology, 38(10), 1051-1057. https://doi.org/10.1093/jpepsy/jst058

Becker, S.P. (2019). Sluggish cognitive tempo: The need for global inquiry. World Psychiatry, 18(2), 237-238. https://doi.org/10.1002/wps.20639

Becker, S.P., \& Barkley, R.A. (2021), Field of daydreams? Integrating mind wandering in the study of sluggish cognitive tempo and ADHD. JCPP Advances, 1(1), e12002. https://doi.org/10.1111/jcv2.12002

Brown, T. (2002). DSM-IV: ADHD and executive function impairments. Advanced Studies in Medicine, 2(25), 910-914.

Bruchmüller, K., Margraf, J., \& Schneider, S. (2012). Is ADHD diagnosed in accord with diagnostic criteria? Overdiagnosis and influence of client gender on diagnosis. Journal of Consulting and Clinical Psychology, 80(1), 128-138. https://do org/10.1037/a0026582

Burke, A., Austin, T., \& Waldeck, C. (2011). Adult ADHD in a student population: Preliminary findings. Journal of Psychology in Africa, 21(1), 27-32. https://doi.org /10.1080/14330237.2011.10820426

Cohen, J. (1992). A power primer. Psychological Bulletin, 112(1), 155-159. https://doi. org/10.1037/0033-2909.112.1.155

Flannery, A.J., Luebbe, A.M., \& Becker, S.P. (2017). Sluggish cognitive tempo is associated with poorer study skills, more executive functioning deficits, and greater impairment in college students. Journal of clinical psychology, 73(9), 1091-1113. https://doi.org/10.1002/jclp.22406

Foxcroft, C., Paterson, H., Le Roux, N., \& Herbst, D. (2004). The test use patterns and needs of psychological assessment practitioners. Pretoria: Human Sciences Research Council.

Jacobson, L.A., Murphy-Bowman, S.C., Pritchard, A.E., Tart-Zelvin, A., Zabel, T.A., \& Mahone, E.M. (2012). Factor structure of a sluggish cognitive tempo scale in clinically referred children. Journal of Abnormal Child Psychology 4O(8), 1327-1337. https://doi.org/10.1007/s10802-012-9643-6
Laher, S., \& Cockcroft, K. (2013). Psychological assessment in South Africa: Research and applications. Johannesburg: Wits University Press.

Lahey, B.B. (2001). Should the combined and predominantly inattentive types of ADHD be considered distinct and unrelated disorders? Not now, at least. Clinical Psychology: Science and Practice, 8(4), 494-497. https://doi.org/10.1093/ clipsy.8.4.494

Lee, S. Burns, G.L., Beauchaine, T.P., \& Becker, S.P. (2016). Bifactor Latent Structure of Attention-Deficit/Hyperactivity Disorder (ADHD)/Opposition Defiant Disorder. Psychological Assessment, 28(8), 917-928. https://doi.org/10.1037/pas0000232

Levy, F., Hay, D.A., McStephen, M., Wood, C., \& Waldman, I. (1997). ADHD: A category or a continuum? Genetic analysis of a large scale twin study. Journal of the American Academy of Child and Adolescent Psychiatry, 36, 737-744. Journal of AttentionDisorders, 2(2),129-129. https://doi.org/10.1177/108705479700200206

Maher, J.M., Markey, J.C., \& Ebert-May, D. (2013). The other half of the story: Effect size analysis in quantitative research. CBE Life Sciences Education, 12(3), 345-351. https://doi.org/10.1187/cbe.13-04-0082

Milich, R., Balentine, A.C., \& Lynam, D.R. (2001). ADHD combined type and ADHD predominantly inattentive type are distinct and unrelated disorders. Clinical Psychology: Science and Practice, 8(4), 463-488. https://doi.org/10.1093/ clipsy.8.4.463

Pallant, J. (2013). SPSS survival manual: A step by step guide to data analysis using IBM SPSS (4th ed.). Crows Nest: Allen \& Unwin.

Shanahan, M., Pennington, B., Yerys, B., Scott, A., Boada, R., Willcutt, E., ... DeFries, J. (2006). Processing speed deficits in attention deficit/hyperactivity disorder and reading disability. Journal of Abnormal Child Psychology, 34(5), 584-601. https:// doi.org/10.1007/s10802-006-9037-8

Schellack, N., \& Meyer, J. (2012). The management of attention-deficit/ hyperactivity disorder in children. South African Pharmacy Journal, 79(10), 12-20.

Sullivan, G.M., \& Feinn, R. (2012). Using effect size-or why the $p$ value is not enough Journal of Graduate Medical Education, 4(3), 279-282. https://doi.org/10.4300/ JGME-D-12-00156.1

Van Eeden, R. (1991). Manual for the Senior South African Individual Scale-Revised (SSAIS-R). Part 1: Background and standardization. Pretoria: Human Sciences Research Council.

Van Eeden, R. (1997). Manual for the Senior South African Individual Scale - Revised (SSAIS-R): Background and standardisation. Pretoria: Human Sciences Research Council.

Wilens, T.E., \& Spencer, T.J. (2010). Understanding attention-deficit/hyperactivity disorder from childhood to adulthood. Postgraduate Medicine, 122(5), 97-109. https://doi.org/10.3810/pgm.2010.09.2206 